Nota de investigación

\title{
Primer reporte de Bacillus spp. entomopatógenas al Melanaphis sacchari Zehntner (Hemiptera: Aphididae)
}

\author{
Erubiel Toledo-Hernández ${ }^{1}$ \\ Stazie Kimberly Olivera-Cruz ${ }^{1}$ \\ Jeiry Toribio-Jiménez ${ }^{1}$ \\ Yanet Romero-Ramírez ${ }^{1}$ \\ Caleb C. Lormendez ${ }^{2}$ \\ Guadalupe Peña-Chora ${ }^{2 \S}$ \\ ${ }^{1}$ Universidad Autónoma de Guerrero-Facultad de Ciencias Químico Biológicas. Avenida Lázaro Cárdenas \\ s/n, Ciudad Universitaria, Chilpancingo, Guerrero, México. CP. 39070. Tel. 7474725503. \\ (erubielth@hotmail.com; $\quad$ stazie_oliver@hotmail.com; $\quad$ jeiryjimenez2014@gmail.com; \\ yanetromero7@gmail.com). ${ }^{2}$ Universidad Autónoma del Estado de Morelos-Centro de Investigaciones \\ Biológicas. Avenida Universidad núm. 1001, Cuernavaca, Morelos, México. CP. 62209. Tel. 7773297029. \\ (calefo@hotmail.com). \\ §Autor para correspondencia: penacg@uaem.mx.
}

\section{Resumen}

Debido a la falta de conocimiento de bacterias patógenas a Melanaphis sacchari, el objetivo de este trabajo fue evaluar la patogenicidad de cepas bacterianas contra este áfido. En la Universidad Autónoma de Guerrero en 2019 se llevaron a cabo los bioensayos in vitro. Mediante ingesta en dieta contaminada, se evaluaron cuatro cepas en dos tratamientos de 10 y $100 \mu \mathrm{g} \mathrm{ml}^{-1}$ de proteína total. Los bioensayos demostraron que las cepas fueron patógenas al áfido, ocasionando una mortalidad a las $48 \mathrm{~h}$ de entre el $35 \pm 8 \%$ al $63 \pm 12 \%$ a una concentración de $10 \mu \mathrm{g} \mathrm{ml}^{-1}$. En tanto que, a una concentración de $100 \mu \mathrm{g} \mathrm{ml}^{-1}$ la mortalidad fue de alrededor del $48 \pm 4 \%$ al $90 \pm 7 \%$. Las cepas más virulentas contra el áfido a una concentración de $10 \mu \mathrm{g} \mathrm{ml}^{-1}$ fueron la ETH-109 y ETH117 , ocasionando una mortalidad de $58 \pm 8 \%$ y $63 \pm 12 \%$, respectivamente. Mientras que, a la concentración de $100 \mu \mathrm{g} \mathrm{ml}^{-1}$ la cepa más virulenta fue la ETH-109 causando una mortalidad de $90 \pm 7 \%$, seguida de la cepa ETH-117 con un $73 \pm 5 \%$ de áfidos muertos.

Palabras clave: bacterias, entomopatógeno, plaga, sorgo.

Recibido: enero de 2021

Aceptado: marzo de 2021 
El pulgón amarillo Melanaphis sacchari Zehntner (Hemiptera: Aphididae), es un insecto plaga originario de África y que actualmente se encuentra distribuido en Asia, Australia, Centro y Sudamérica, alrededor de 20 cultivos pertenecientes a la familia Poaceae son sus hospederos (Singh et al., 2004). En noviembre de 2013, esta plaga exótica se reportó por primera vez en cultivos de sorgo del estado de Tamaulipas, México. Las afectaciones fueron severas, se estimó que hubo de 30 a $100 \%$ de daños al cultivo en las temporadas de primavera-otoño, catalogándose como una nueva plaga de la región (Rodríguez-Bosque y Terán, 2015).

Para el control de este insecto, estudios en campo demostraron que productos como imidacloprid, sulfoxaflor, espirotetramat, tiametoxam y metamidofos, presentan una efectividad mayor a $90 \%$ de mortalidad (Rodríguez-Bosque y Terán, 2015). Por otra parte, el control biológico es una herramienta alternativa más amigable con el medio ambiente para el manejo de plagas insectiles, de la cual existen trabajos exitosos realizados alrededor del mundo (Ruiu, 2015; Lacey et al., 2015).

Generalmente, la familia Bacillaceae ha representado el grupo de bacterias entomopatógenas, aportando al mercado la mayor cantidad de productos y especies para el control biológico. Algunas de las especies representantes de esta familia son; Bacillus thuringiensis, Lysinibacillus sphaericus, Paenibacillus spp. y Brevibacillus laterosporus (Ruiu, 2015). En la actualidad, la compañía Estadounidense Marrone ${ }^{\circledR}$ Bio Innovations ofrece dos productos a base de bacterias para el control de áfidos, ácaros y otros insectos, siendo estos Grandevo ${ }^{\circledR}$ (Chromobacterium subtsugae) y Venerate $^{\circledR}$ (Burkholderia spp., strain A396) (Toennisson y Burrack, 2018).

Sin embargo, actualmente existen escasos reportes de bacterias del género Bacillus patógenas a áfidos, Torres-Quintero et al. (2016) reportaron que 17 cepas de Bacillus thuringiensis eran patógenas al áfido del melocotonero, Myzus persicae (Sulzer); no obstante, a la fecha no hay reportes de bacterias patógenas al pulgón amarillo $M$. sacchari. De acuerdo con los antecedentes y debido a la falta de conocimiento sobre bacterias patógenas a esta plaga, se estableció como objetivo, evaluar la patogenicidad de diferentes cepas bacterianas contra $M$. sacchari.

Para establecer el pie de cría de $M$. sacchari, se utilizaron plantas jóvenes ( 2 meses) de sorgo de la variedad M550. Especímenes de áfidos colectados en cultivos de sorgo de la zona oriente del estado de Morelos (18.7669 ${ }^{\circ}$ latitud norte, $98.8970^{\circ}$ longitud oeste) fueron utilizados para infestar las plantas, colocándolas en jaulas hechas con tela de organza y puestas en jaulas de $1 \mathrm{~m}^{3}$ con malla antiáfidos. Las cepas para evaluar fueron facilitadas por el Laboratorio de Parasitología Vegetal del Centro de Investigaciones Biológicas, de la Universidad Autónoma del Estado de Morelos (UAEM), las cuales habían sido aisladas de cadáveres de insectos del orden Hemiptera.

Para los bioensayos, las bacterias fueron crecidas en medio de cultivo HCT ( $5 \mathrm{~g}$ triptona; $2 \mathrm{~g}$ medio ácidos casamino; $15 \mathrm{~g}$ agar) ajustando el $\mathrm{pH}$ a 7.5 y esterilizando mediante autoclave a $120^{\circ} \mathrm{C}$ por 20 min a 15-20 psi. Después de la esterilización se suplementó el medio de cultivo con $\mathrm{KH}_{2} \mathrm{PO}_{4}$, $3.4 \mathrm{~g} \mathrm{~L}^{-1}$; $\mathrm{MgSO}_{4} .7 \mathrm{H}_{2} \mathrm{O}, 0.012 \mathrm{~g} \mathrm{~L}^{-1} ; \mathrm{MnSO}_{4} .4 \mathrm{H}_{2} \mathrm{O}, 0.003 \mathrm{~g} \mathrm{~L}^{-1}$; ZnSO $4.7 \mathrm{H} 2 \mathrm{O}, 0.0028 \mathrm{~g} \mathrm{~L}^{-1}$; Fe $\left(\mathrm{SO}_{4}\right)_{3} .7 \mathrm{H}_{2} \mathrm{O}, 0.02 \mathrm{~g} \mathrm{~L}^{-1} ; \mathrm{CaCl}_{2} .2 \mathrm{H}_{2} \mathrm{O}, 0.147 \mathrm{~g} \mathrm{~L}^{-1}$; y glucosa $3 \mathrm{~g} \mathrm{~L}^{-1}$, los cuales fueron previamente esterilizados bajo las mismas condiciones anteriormente descritas (Torres-Quintero et al., 2016).

Las bacterias fueron sembradas en caja Petri dejándolas en incubación a $30 \pm 1{ }^{\circ} \mathrm{C}$ durante $72 \mathrm{~h}$. Una vez esporulado $80 \%$ de las bacterias, fue recuperado el complejo espora-cristal en $1 \mathrm{ml}$ de agua destilada estéril, agregando $1 \mathrm{mM}$ de PMSF (fenil metanosulfonil fluoruro). La proteína total 
se cuantificó mediante la técnica de Bradford (1976) a $595 \mathrm{~nm}$. El sistema de alimentación utilizado en los bioensayos fue el reportado por Torres-Quintero et al. (2013), en el recipiente se agregaron $2 \mathrm{ml}$ de dieta reportada por Toledo-Hernández et al. (2018), colocando posteriormente la membrana de Parafilm para voltearlo y unirlo con el otro vaso de plástico, al cual se le colocó la tela de organza para impedir que los pulgones escaparan.

En los bioensayos de patogenicidad se emplearon dos tratamientos, 10 y $100 \mu \mathrm{g} \mathrm{ml}$ de proteína total adicionada en la dieta. Posteriormente, fueron colocados 15 pulgones en cada uno de los sistemas de alimentación, evaluando la mortalidad a las 48 h. El bioensayo se dejó en incubación a $30 \pm 1{ }^{\circ} \mathrm{C}$ con una humedad relativa de $70 \pm 5 \%$. Cada uno de los experimentos se realizó por duplicado con seis repeticiones cada uno, el control negativo fue únicamente la dieta de sacarosa al $30 \%$.

Para la visualización de las bacterias al microscopio a 100X (Nikon Eclipse 80i), estás fueron sembradas en cajas Petri con medio HCT e incubadas $30 \pm 1{ }^{\circ} \mathrm{C}$ y a las $48 \mathrm{~h}$ se hicieron preparados de biomasa bacteriana en portaobjetos. Los datos de mortalidad fueron analizados mediante un Anova de una vía, haciendo una comparación de medias mediante la prueba de Tukey con un nivel de significancia de $p<0.05$, para el análisis estadístico se utilizó el software Sigma Plot 11.0. La unidad experimental fue de 15 pulgones por sistema de alimentación. Se realizaron 2 réplicas con seis repeticiones para cada una de las concentraciones de proteína total evaluada.

En un lapso de dos meses se pudo establecer un pie de cría de M. sacchari libre de insectos parasitados, aunado a que este insecto presenta una alta tasa de reproducción. En los bioensayos de patogenicidad a $10 \mu \mathrm{g} \mathrm{ml}^{-1}$ de proteína total, se determinó a las 48 h que las cepas ETH-109 y ETH-117 fueron las más virulentas, ya que ocasionaron una mayor mortalidad del $\mathrm{M}$. sacchari, siendo de alrededor de $58 \pm 8 \%$ y $63 \pm 12 \%$, respectivamente (Figura 1). En tanto que, las cepas ETH-116 y ETH-118 causaron una mortalidad del $35 \pm 8 \%$ y $36 \pm 10 \%$ de los áfidos (Figura 1).

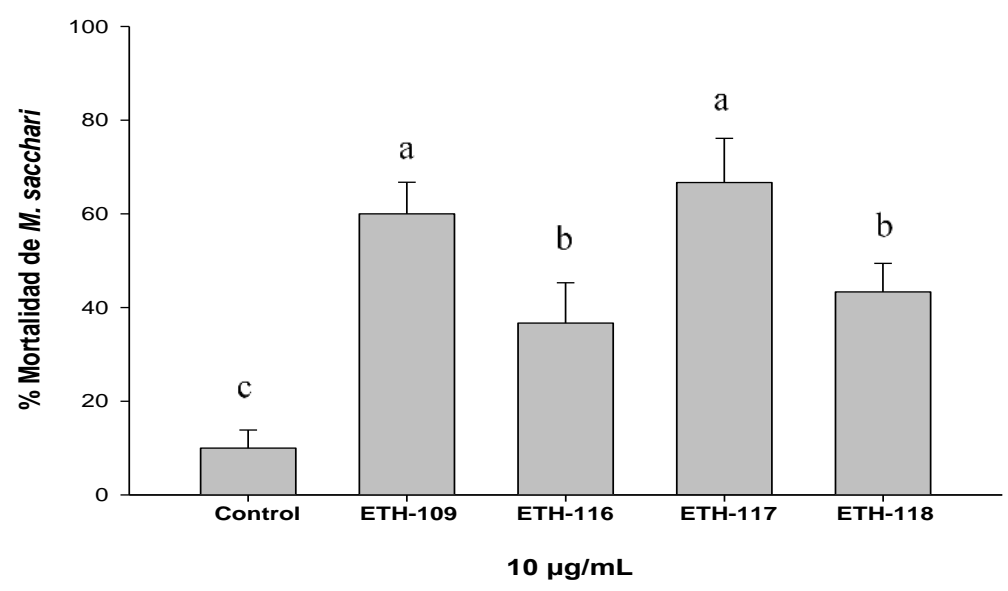

Figura 1. Patogenicidad de las cepas contra $M$. sacchari a una concentración de proteína total de 10 $\mu \mathrm{g} \mathrm{ml}^{-1}$. Bioensayo evaluado a las $48 \mathrm{~h}$. Barras con letra diferente denotan diferencia significativa de acuerdo con la prueba de Tukey $p<0.05$. 
Por otra parte, en los bioensayos de $100 \mu \mathrm{g} \mathrm{ml}^{-1}$ de proteína total se determinó a las $48 \mathrm{~h}$ que la cepa ETH-109 fue la más virulenta contra $M$. sacchari, provocando una mortalidad de $90 \pm 7 \%$, seguida de la cepa ETH-117 con $73 \pm 5 \%$ de áfidos muertos (Figura 2). En tanto que, las cepas ETH-116 y ETH-118 ocasionaron mortalidades de alrededor del $58 \pm 12 \%$ y $48 \pm 4 \%$, respectivamente (Figura 2 ).

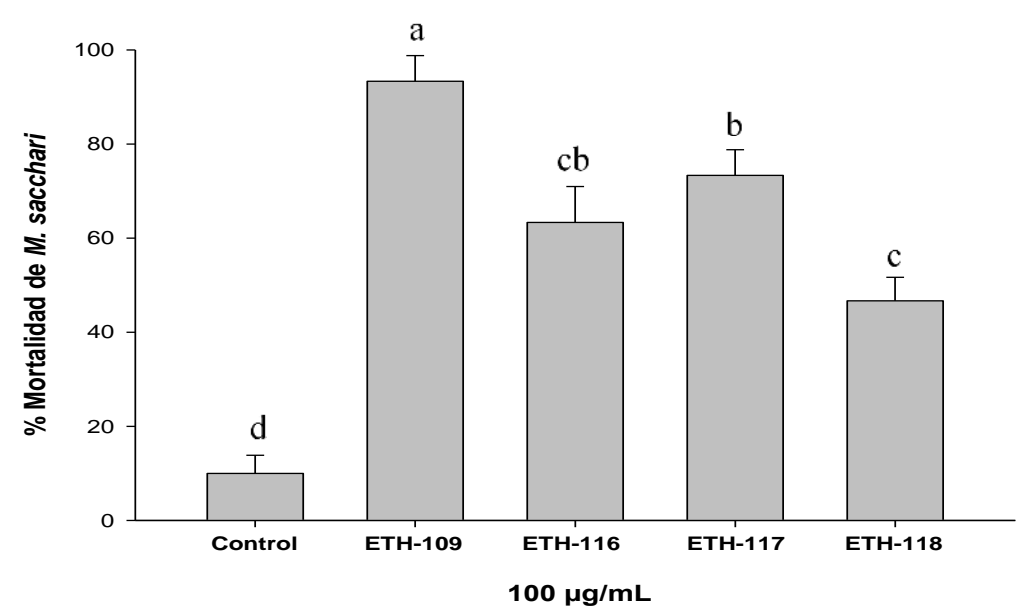

Figura 2. Patogenicidad de las cepas contra $M$. sacchari a una concentración de proteína total de 100 $\boldsymbol{\mu g} \mathbf{~ m l}^{-1}$. Bioensayo evaluado a las $48 \mathrm{~h}$. Barras con letra diferente denotan diferencia significativa de acuerdo con la prueba de Tukey $p<0.05$.

En el análisis de las muestras bacterianas al microscopio, se observó que las cepas presentan características morfológicas del tipo bacilo, un bastón alargado el cual era de diferente tamaño en cada bacteria. Además, se observó en cada una de las cepas la estructura celular conocida como esporangio, la cual consiste en la formación de un complejo espora-cristal, siendo esta una característica particular del género Bacillus (Figura 3a y 3b).

a)

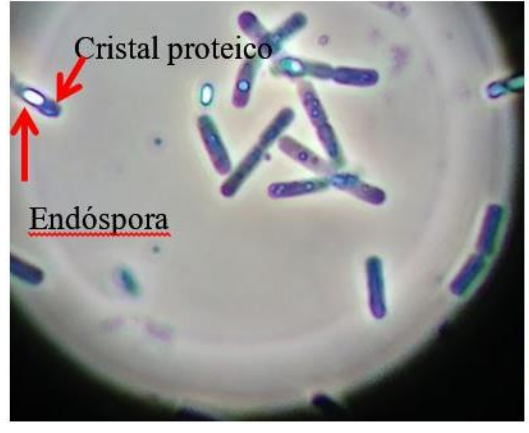

b)

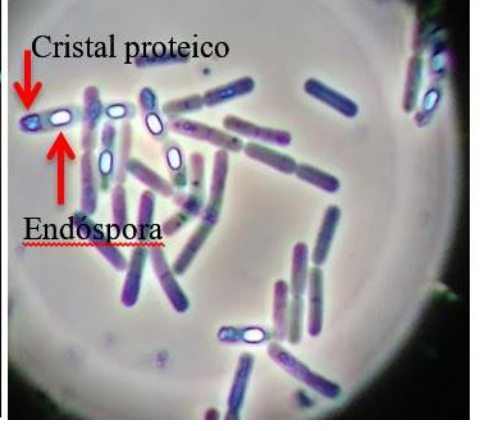

Figura 3. a) Cepa ETH-118; y b) cepa ETH-116: presentan la estructura conocida como esporangio, dentro de la cual se visualiza el cristal proteico y endóspora, características particulares del género Bacillus.

A la fecha solo existe un estudio que reporta diferentes cepas del género Bacillus patógenas al áfido del melocotonero, Myzus persicae Sulzer. En este trabajo Torres-Quintero et al. (2016) evaluaron la patogenicidad de bacterias aisladas de cadáveres de insectos del Orden Hemiptera, cepas que 
corresponden a la especie Bacillus thuringiensis. Su estudio consistió en un tamiz de patogenicidad con aproximadamente 40 cepas de $B$. thuringiensis contra $M$. persicae, encontrando que 17 bacterias eran patógenas mediante la ingesta de proteína total $\left(10 \mu \mathrm{g} \mathrm{ml}^{-1}\right)$, ocasionando la mortalidad del áfido hasta en $88 \%$ a las $72 \mathrm{~h}$. Aunque la virulencia de las cepas reportadas por Torres-Quintero et al. (2016) es mayor a las nuestras a $10 \mu \mathrm{g} \mathrm{ml}^{-1}$ (ETH-109 $58 \pm 8 \%$ y ETH-117 $63 \pm 12 \%$ ), no es posible hacer una comparación directa, ya que las cepas utilizadas en nuestro estudio se evaluaron hasta las $48 \mathrm{~h}$, además de que ambos trabajos fueron realizados contra diferente especie de áfido.

Cabe destacar que entre especies de áfidos la estructura del sistema digestivo puede ser diferente Ponsen (1991) presentó evidencia de diferencias morfológicas e histológicas en el sistema digestivo entre especímenes de la misma especie. Estas diferencias estructurales influyen en la susceptibilidad del hospedero, aumentando o disminuyendo la virulencia de las cepas con respecto al huésped.

\section{Conclusiones}

Se determinó que las cuatro cepas evaluadas son patógenas a Melanaphis sacchari y pertenecen al género Bacillus. En tanto que, las cepas más virulentas contra el áfido a $10 \mu \mathrm{ml}^{-1}$ de proteína total fue la ETH-109 y ETH-117 (58 $\pm 8 \%$ y $63 \pm 12 \%$ de mortalidad, respectivamente. Mientras que, a $100 \mu \mathrm{l} \mathrm{ml}^{-1}$ la cepa más virulenta fue la ETH-109, seguida de la cepa ETH-117 (90 $\pm 7 \%$ y $73 \pm 5 \%$, respectivamente.

\section{Literatura citada}

Bradford, M. M. 1976. A rapid and sensitive method for the quantitation of microgram quantities of protein utilizing the principle of protein-dye binding. Anal. Biochem. 72(1-2):248-254.

Toennisson, A. and Burrack, H. 2018. Efficacy of biopesticides against aphids in tobacco, 2017. Arthropod Manag. Tests. 43(1):1-2.

Lacey, L. A.; Grzywacz, D.; Shapiro-Ilan, D. I.; Frutos, R.; Brownbridge, M. and Goettel, M. S. 2015. Insect pathogens as biological control agents: Back to the future. J. Invertebr. Pathol. 132:1-41.

Ponsen, M. B. 1991. Structure of the digestive system of aphids, in particular Hyalopterus and Coloradoa, and its bearing on the evolution of filter chambers in Aphidoidea. Wageningen. Wageningen Agricultural University Press. 91(5):1-61.

Rodríguez-Bosque, L. A. and Terán, A. T. 2015. Melanaphis sacchari (Hemiptera: Aphididae): a new sorghum insect pest in Mexico. Southwest. Entomol. 40(2):433-434.

Ruiu, L. 2015. Insect pathogenic bacteria in integrated pest management. Insects. 6(2):352-367.

Singh, B. U.; Padmaia, P. G. and Seetharama, N. 2004. Biology and management of the sugarcane aphid, Melanaphis sacchari (Zehntner) (Homoptera: Aphididae), in sorghum: a review. Crop Prot. 23(9):739-755.

Toledo-Hernández, E.; Hernández-Velázquez, V. M. and Peña-Chora, G. 2018. An artificial diet for the sugarcane aphid (Melanaphis sacchari Zehntner) (Hemiptera: Aphididae) with potential uses for in vitro toxicological studies. Fla. Entomol. 101(3):395-398. 
Torres-Quintero, M. C.; Arenas-Sosa, I.; Hernández-Velázquez, V. M.; Suárez-Rodríguez, R. and Peña-Chora, G. 2016. Characterization of Bacillus thuringiensis (Bacillaceae) strains pathogenic to Myzus persicae (Hemiptera: Aphididae) Fla. Entomol. 99(4):639-643.

Torres-Quintero, M. C.; Arenas-Sosa, I.; Peña-Chora, G. and Hernández-Velázquez, V. M. 2013. Feeding chamber for Myzus persicae culture (Hemiptera: Aphididae). Fla. Entomol. 96(4):1600-1602. 